\title{
Assessing the value of the Ambulatory Glucose Profile in clinical practice
}

\author{
STEPHAN MATTHAEI
}

\begin{abstract}
Glycated haemoglobin ( $\mathrm{HbA}_{1 \mathrm{c}}$ ) is a measure of mean blood glucose levels over time. It is not a good indicator of day-today diabetes control and may not reveal variability in blood glucose. Continuous glucose monitoring (CGM) enables the real-time monitoring of glycaemic variability, potentially addressing issues such as episodic hypoglycaemia, hyperglycaemia, and the risk of complications associated with significant glycaemic excursions. Given the quantity of data produced by CGM, there is a need for standardised analysis to enable patterns of blood glucose variation to be revealed. This need has been addressed by the development of specific software - the Ambulatory Glucose Profile (AGP) - which combines inputs from multiple days of CGM data and collates them into a single 24-hour period, making glycaemic patterns more recognisable. In this study, European diabetologists were asked to evaluate the AGP software and report their findings by means of a questionnaire. The results support the use of AGP for analysis of patient glucose data and informing subsequent treatment decisions. When shared with the patient, the AGP results were found to be an effective basis for education, helping achieve better understanding of glycaemic variability and increasing involvement in diabetes self-management.

Br J Diabetes Vasc Dis 2014;14:148-152
\end{abstract}

Key words: Ambulatory Glucose Profile, glucose variability, glucose monitoring, glucose data, continuous glucose monitoring, hypoglycaemia risk assessment, glycaemic excursions

\section{Introduction}

Since the publication of the $\mathrm{DCCT}, \mathrm{HbA}_{1 \mathrm{c}}$ has been considered the gold standard for measuring diabetes control, 1,2 as its correlation with the incidence -of microvascular and macrovascular

Diabetes-Zentrum Quakenbrück, Fachabteilung für Diabetologie, Endokrinologie \& Stoffwechselerkrankungen am Christlichen Krankenhaus, Quakenbrück, Germany

Address for correspondence: Professor Stephan Matthaei Diabetes-Zentrum Quakenbrück, Fachabteilung für Diabetologie, Endokrinologie \& Stoffwechselerkrankungen am Christlichen Krankenhaus, Quakenbrück, Germany.

Tel: +49 (0)5431 152830

E-mail: S.Matthaei@ckq-gmbh.de

http://dx.doi.org/10.15277/bjdvd.2014.045

\author{
Abbreviations and acronyms \\ AGP \\ CGM \\ DCCT \\ FDA \\ $\mathrm{HbA}_{1 \mathrm{c}}$ \\ IDC \\ IQR \\ SMBG \\ Ambulatory Glucose Profile \\ continuous glucose monitoring \\ Diabetes Control and Complications Trial \\ Food and Drug Administration \\ glycated haemoglobin \\ International Diabetes Centre \\ interquartile range \\ self-monitoring of blood glucose
}

complications has been conclusively established in several large, randomised studies. ${ }^{3-6}$ Given that red blood cells have a life-span of approximately 120 days, $\mathrm{HbA}_{1 \mathrm{c}}$ is generally considered to reflect mean blood glucose over this period and is therefore not a good indicator of day-to-day diabetes control. ${ }^{1}$ This is of particular importance when considering the need to avoid significant extremes of glucose variability and the associated risk of hypoglycaemia or hyperglycaemia. 1,7,8 There is also evidence that glycaemic variability may have a greater association with the risk of diabetic complications than mean $\mathrm{HbA}_{1 c}$. The DCCT study found that, even when $\mathrm{HbA}_{1 c}$ was comparable, the risk of progression of retinopathy was significantly greater in conventionally treated patients compared with intensively treated patients after 5 to 9 years $(p<0.01) .9,10$ One potential explanation for this outcome is the greater frequency and magnitude of glycaemic excursions in conventionally treated patients. ${ }^{9}$ Reducing glucose variability may therefore be an important aspect of effective glucose control. ${ }^{9}$

A significant challenge to effectively understanding glycaemic variability is to find an accurate and standardised method of glucose data collection and analysis. ${ }^{1}$ CGM offers the possibility of recording diurnal glucose patterns ${ }^{11}$ although the data produced by such devices is often unmanageable. There is, therefore, a need for standardised analysis that is easy to understand and which will reveal the important patterns of blood glucose variation. Mazze et al.,12 in collaboration with the IDC, Minneapolis, Minnesota, have produced a software approach called the AGP. ${ }^{13}$ AGP standardises clinical terms and key metrics and presents glucose data visually, making it easy to interpret.

To produce an AGP report, the software combines all CGM data from several days or weeks into a single 24-hour period. The programme then applies mathematical algorithms to help present glycaemic patterns. ${ }^{11}$ The first component of the AGP to be plotted is the median curve ( $50^{\text {th }}$ percentile), which shows the median glucose value for every time point and is a representation of glucose stability. The curves immediately above and 
Figure 1. Development of an Ambulatory Glucose Profile (AGP) report, plotting patterns in the blood glucose values displayed in a modal day report

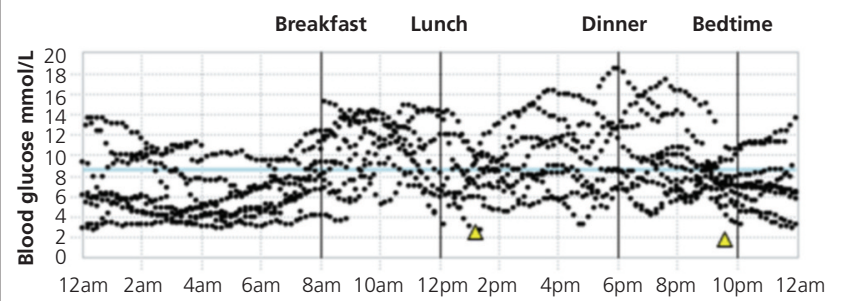

Sensor reading $\Delta$ Low episodes $<2.8 \mathrm{mmol} / \mathrm{L}$ (sensor)

1. Modal day displaying all blood glucose readings obtained

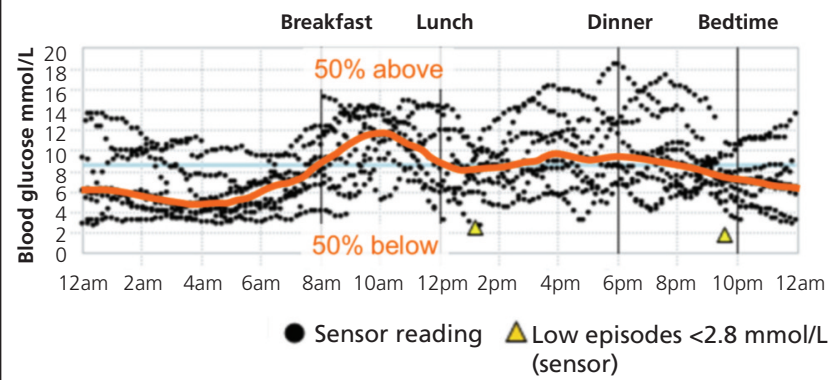

2. Hourly median line is added

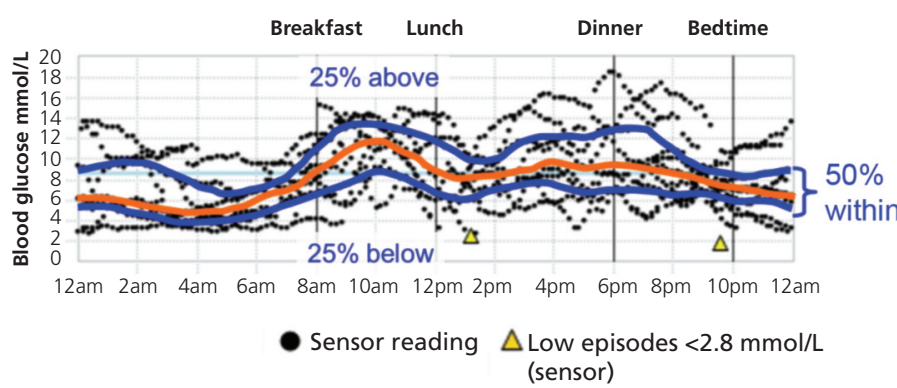

3. Hourly quartile lines are added

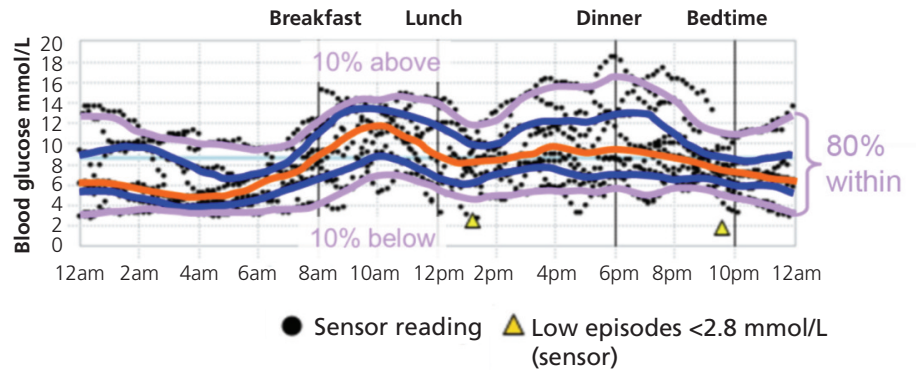

4. Hourly decile lines are added to complete the AGP below the median curve define the IQR. The IQR is used to represent glucose variability as it shows the span of $50 \%$ of glucose values. The $10^{\text {th }}$ and $90^{\text {th }}$ percentile curves - the two curves on either side of the IQR - track glucose excursions. Thus, when the five curves appear close, there is a fairly high degree of certainty that the variability will be low. By representing the glucose values in this way, the AGP visually and statistically portrays overall diurnal glucose characteristics of glucose exposure, variability and stability, and hence it is possible to rapidly determine whether there is an underlying pattern (Figures 1 and 2).

Bergenstal et al. undertook an analysis of the AGP software by asking a panel of US diabetes specialists for feedback on its clinical utility. ${ }^{13}$ Based on their conclusions and recommendations, the
Figure 2. Ambulatory Glucose Profile (AGP) report of 14 days of Continuous Glucose Monitoring (CGM) data, displayed by time to show the spread of glucose values within each time interval. The dark blue line is the median curve $\left(50^{\text {th }}\right.$ percentile) and shows the median glucose value for each time point. The blue shaded area represents the interquartile range (IQR). The outlier values (lowest and highest 10\%) are represented by the light blue shaded area.

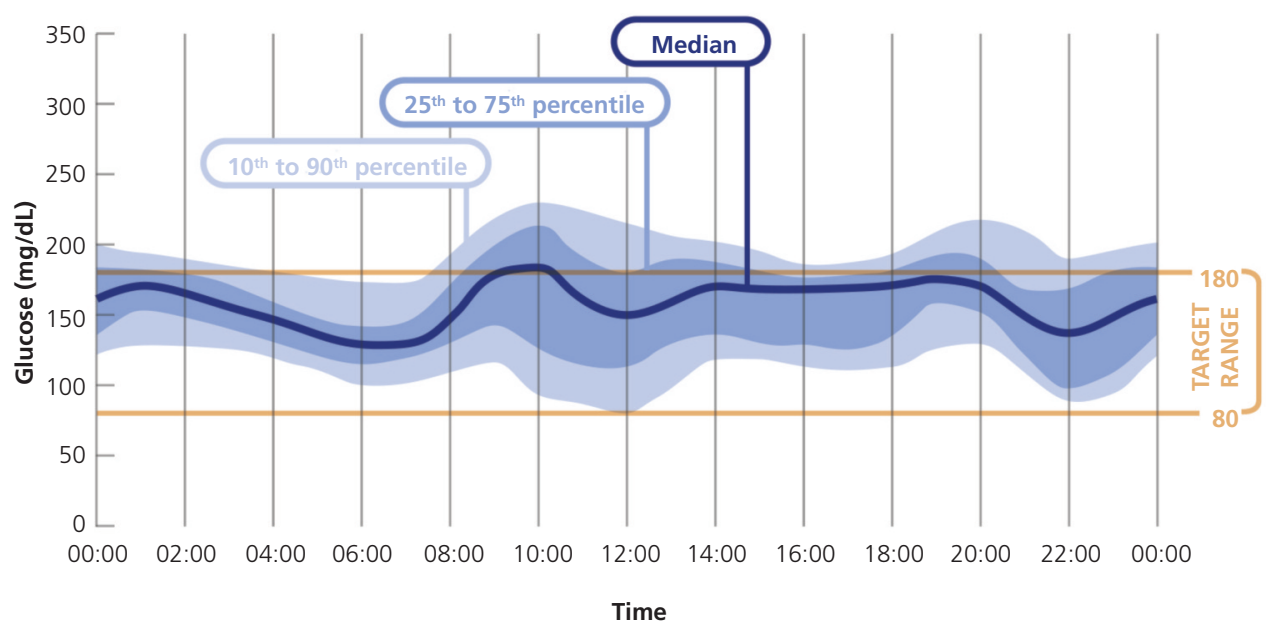


US FDA announced its support for 'more standardised reporting and analysis of data and information obtained from current glucose monitoring devices. ${ }^{14}$ AGP has recently become available for commercial use in Europe and so an expert panel of European diabetologists was set up to further evaluate this approach. The methods and results of this are described here.

\section{Methods}

A working group of diabetes specialists from France, Germany, Italy, Spain, and United Kingdom was established. Each specialist was provided with a FreeStyle Navigator II (Abbott Diabetes Care, Alameda, California, USA), consisting of CGM sensor, transmitter and receiver ${ }^{15}$ and was asked to analyse data using AGP Software extension to the FreeStyle CoPilot Health Management System software (Abbott Diabetes Care). Patients with type 1 and type 2 diabetes were included. No specific protocol was set and the working group members were asked to:

- Assess AGP in diabetes patients for whom CGM review would normally be indicated

- Assess the benefit of acquiring 14 days of continuous data per patient

A monitoring period of 14 days was selected based on evidence that a minimum of 14 days of CGM is sufficient for identification of glucose patterns ${ }^{16}$ and that this period of sensor wear is achievable with the FreeStyle Navigator II. ${ }^{17}$

Feedback was gathered via a structured online research questionnaire following 3 months of experience. This research included questions on patient demographics to understand in which clinical situations AGP was examined in, and whether both insulin and non-insulin-treated patients were assessed using the technique. The results were analysed and presented to an expert panel of six diabetes specialists for further consideration.

\section{Results}

In the working group 16 diabetes specialists provided data from 59 patients. Of these, 53 patients had type 1 diabetes and the average number of days of data collected per patient was 12.46 (Table 1). Although no protocol was set to dictate specific patient types that should be involved, AGP was mostly used for those who exhibited poor glycaemic regulation and unpredictable glucose excursions. This included patients who had previously experienced unidentified hypoglycaemia or overnight hypoglycaemia, and whose $\mathrm{HbA}_{1 \mathrm{c}}$ did not match with their SMBG values.

The following is a summary of the most informative statistics and responses from the online questionnaire that the working group was asked to complete.

\section{Ease of use and interpretation}

Overall, 11/15 of physicians who responded to the questionnaire found AGP easy or very easy to use; $11 / 15$ found the report easy to interpret and 13/15 felt that they could interpret it intuitively, without the need for formal training.

\section{Usefulness in clinical practice}

It was agreed by $12 / 14$ respondents that AGP was useful or very useful in clinical practice and 11/15 agreed that it enabled better understanding of a patient's glycaemic control in comparison with other methods of analysing CGM data. Feedback confirmed that the system enabled the clinician to quickly establish where the main problems in glycaemic control occurred and to consider potential solutions. Of the respondents, 14/15 used the AGP reports in discussion with their patients and, of these, 13/14 agreed that this was useful and served as an educational tool in helping a patient's overall understanding of their diabetes. The respondents considered the role of AGP in patient education as its greatest potential benefit, helping patients better understand their glycaemic control and to become more involved in the management of their diabetes.

\section{Clinical utility of AGP}

Respondents identified the main clinical situations where AGP was considered of value as:

- Identifying reasons for a mismatch between the patient's glycaemic profile and $\mathrm{HbA}_{1 \mathrm{c}}$ results

- Assessing a patient's glucose levels versus target range

- Understanding extent and causes of high blood glucose variability

- Assessing suitability of treatment

- Assessing whether it is safe to increase insulin dose

It was suggested that AGP would be less useful for patients who have poor adherence to treatment, or where there is no information available on food and carbohydrate intake, or physical activity. Furthermore, AGP was identified as not being as valuable for patients who are reluctant to make changes to improve their glycaemic control.

A majority (12/15) of respondents agreed that AGP will indicate direction for clinical decision-making on potential changes to the prescribed intervention and 13/15 would recommend its use to other healthcare professionals caring for people with diabetes.

\section{Discussion}

The results of this study support previously published evidence that AGP represents a potentially useful tool for analysing individual patient glucose data, and that this approach clearly highlights trends in the variability of a glucose profile, informing subsequent treatment decisions. ${ }^{13,18,19}$ The feedback received in this study suggests a key role for AGP as a tool for patient education.

The responses suggest that $A G P$ enables a better understanding of a patient's glycaemic control in comparison with other methods of CGM data, in particular, the availability of an IQR was considered to be more valuable. It was reported that the evaluation of glucose variability, and hypoglycaemic risk was easier than the Medtronic iPro2 system. However, the insulin dose information available on the Medtronic CareLink Pro was considered to be a benefit that is not present in this version of the AGP report.

As the use of AGP in clinical practice is not yet well reported in the published literature, it remains important to identify in 
Table 1 Feedback on the use of the Ambulatory Glucose Profile (AGP) in clinical practice gathered via an online questionnaire. Results are displayed by question type, with the responses for each question given alongside the number of diabetes specialists who answered it

\begin{tabular}{|c|c|c|c|c|c|c|c|}
\hline \multirow{2}{*}{$\begin{array}{l}\text { Number of diabetes specialists who } \\
\text { responded to the online questionnaire }\end{array}$} & \multicolumn{3}{|l|}{$16 / 16$} & & & & \\
\hline & Total & Type 1 diabetes & Type 2 diabetes & & & & \\
\hline \multirow[t]{2}{*}{ Patients assessed } & 59 & $53 / 59$ & $6 / 59$ & & & & \\
\hline & Pump & Basal/bolus & $\begin{array}{l}\text { Basal with or } \\
\text { without oral }\end{array}$ & Oral only & Premix & & \\
\hline Type of therapy the patients were prescribed & $24 / 58$ & $29 / 58$ & $1 / 58$ & $3 / 58$ & $1 / 58$ & & \\
\hline \multirow{2}{*}{$\begin{array}{l}\text { Average number of days of CGM data } \\
\text { included in each AGP report }\end{array}$} & 12.46 & & & & & & \\
\hline & Very easy & Easy & $\begin{array}{l}\text { Neither easy or } \\
\text { hard }\end{array}$ & Hard & Very hard & & \\
\hline Overall, how easy did you find AGP to use? & $5 / 15$ & $6 / 15$ & $3 / 15$ & $1 / 15$ & $0 / 15$ & & \\
\hline \multirow{2}{*}{$\begin{array}{l}\text { Overall, how easy did you find the AGP } \\
\text { report to interpret? }\end{array}$} & $4 / 14$ & $7 / 14$ & $3 / 14$ & $0 / 14$ & $0 / 14$ & & \\
\hline & Very useful & Useful & $\begin{array}{l}\text { Neither useful or } \\
\text { not useful }\end{array}$ & Not useful & $\begin{array}{l}\text { Not at all } \\
\text { useful }\end{array}$ & & \\
\hline $\begin{array}{l}\text { Overall, how useful did you think AGP was } \\
\text { in your clinical practice? }\end{array}$ & $5 / 14$ & $7 / 14$ & $2 / 14$ & $0 / 14$ & $0 / 14$ & & \\
\hline \multirow{2}{*}{$\begin{array}{l}\text { How useful do you think AGP is as a tool to } \\
\text { identify any problems with a patient's } \\
\text { glycaemic profile and/or the effect of } \\
\text { prescribed interventions? }\end{array}$} & $7 / 15$ & $6 / 15$ & $1 / 15$ & $1 / 15$ & $0 / 15$ & & \\
\hline & Yes & No & Not sure & & & & \\
\hline $\begin{array}{l}\text { Do you think that using AGP could } \\
\text { contribute to time saving within the clinic, } \\
\text { in comparison to using other methods of } \\
\text { analysing CGM data? }\end{array}$ & $9 / 15$ & $1 / 15$ & $5 / 15$ & & & & \\
\hline $\begin{array}{l}\text { When you used AGP for the first time, did } \\
\text { you feel that you could interpret it intuitively } \\
\text { without the need for formal training? }\end{array}$ & $13 / 15$ & $1 / 15$ & $1 / 15$ & & & & \\
\hline $\begin{array}{l}\text { In comparison to using other methods of } \\
\text { analysing CGM data, would you agree that } \\
\text { AGP enables a better understanding of a } \\
\text { patient's glycaemic control? }\end{array}$ & $11 / 15$ & $1 / 15$ & $3 / 15$ & & & & \\
\hline $\begin{array}{l}\text { Do you think that using AGP would give } \\
\text { more confidence in making clinical decisions } \\
\text { to improve a patient's glycaemic control } \\
\text { and/or in changing the interventions for } \\
\text { management of a patient? }\end{array}$ & $12 / 15$ & $1 / 15$ & $2 / 15$ & & & & \\
\hline $\begin{array}{l}\text { Would you recommend using AGP to other } \\
\text { healthcare professionals caring for people } \\
\text { with diabetes? }\end{array}$ & $13 / 15$ & $0 / 15$ & $2 / 15$ & & & & \\
\hline $\begin{array}{l}\text { Did you show any of the patients you } \\
\text { assessed for this evaluation their AGP report } \\
\text { in order to help their understanding of their } \\
\text { glycaemic control? }\end{array}$ & $14 / 15$ & $1 / 15$ & & & & & \\
\hline $\begin{array}{l}\text { Did you find it useful to show the patients } \\
\text { their AGP report as a means of helping them } \\
\text { understand their glycaemic control? }\end{array}$ & $13 / 14$ & $0 / 14$ & $1 / 14$ & & & & \\
\hline \multirow{2}{*}{$\begin{array}{l}\text { Do you think that AGP could be useful as an } \\
\text { educational tool in helping a patient's overall } \\
\text { understanding of their diabetes? }\end{array}$} & $14 / 15$ & $0 / 15$ & $1 / 15$ & & & & \\
\hline & $\begin{array}{l}\text { Assessing the } \\
\text { patient's blood } \\
\text { glucose levels } \\
\text { versus target } \\
\text { range }\end{array}$ & $\begin{array}{l}\text { Assessing extent } \\
\text { and causes of high } \\
\text { blood glucose } \\
\text { variability }\end{array}$ & $\begin{array}{l}\text { Assessing extent } \\
\text { and cause of } \\
\text { hypoglycaemia }\end{array}$ & $\begin{array}{l}\text { Assessing } \\
\text { suitability } \\
\text { of } \\
\text { treatment }\end{array}$ & $\begin{array}{l}\text { Assessing } \\
\text { whether it } \\
\text { is safe to } \\
\text { increase } \\
\text { insulin }\end{array}$ & $\begin{array}{l}\text { Assessing reasons } \\
\text { for a mismatch } \\
\text { between the } \\
\text { patient's } \\
\text { glycaemic profile } \\
\text { and their } \mathrm{HbA}_{1 \mathrm{C}} \\
\text { results }\end{array}$ & Other \\
\hline $\begin{array}{l}\text { In which of the following clinical situations } \\
\text { do you think AGP has value (please tick all } \\
\text { that apply)? }\end{array}$ & $13 / 15$ & $11 / 15$ & $10 / 15$ & $11 / 15$ & $11 / 15$ & $13 / 15$ & $1 / 15$ \\
\hline
\end{tabular}




\section{Key messages}

AGP

- combines inputs from multiple days of CGM data and collates them into a single 24-hour period

- is useful for analysis of glycaemic variability, allowing quick identification of poor glycaemic control to inform treatment decisions

- is useful for patient education

which clinical situations AGP may provide most value. It is clear that the patient's treatment regimen, their adherence, and typical food intake must be considered alongside the AGP report. Daily data should also be reviewed as individual hypoglycaemic episodes may be missed. Therefore, the best method of interpreting the report needs to be established, and this has been identified as an area for future investigation.

In conclusion, AGP is a useful tool for clinical practice in Europe. It offers easily interpretable insights to glycaemic variability, which helps healthcare professionals to readily identify areas of concern and suggest possible solutions.

Conflict of interest S Matthaei has received speaker fees and consultancy fees from Abbott Diabetes Care.

Funding sources This article was initiated and paid for by Abbott Diabetes Care, who provided FreeStyle Navigator Continuous Glucose Monitoring Systems.

None of the AGP working group members received payment for their participation.

Acknowledgements Medical writing support in the form of editing, referencing, journal liaison and factual accuracy checking, has also been provided. However, the views expressed are those of the author.

\section{References}

1. Kowalski AJ, Dutta S. It's time to move from A1c to better metrics for diabetes control. Diabetes Technol Ther 2013;15:194-6. http://dx.doi.org/10.1089/dia.2013.0060

2. DCCT/EDIC Research Group. Modern-day clinical course of type 1 diabetes mellitus after 30 years' duration: the Diabetes Control Intervention and Complications and Pittsburgh Epidemiology of Diabetes Complications experience (1983-2005). Arch Intern Med 2009;169:1307-16. http://dx.doi.org/10.1001/archinternmed.2009.193

3. DCCT Research Group. The effect of intensive treatment of diabetes on the development and progression of long-term complications in insulindependent diabetes mellitus. N Engl J Med 1993;329:977-86.
http://dx.doi.org/10.1056/NEJM199309303291401

4. UKPDS Group. Effect of intensive blood-glucose control with metformin on complications in overweight patients with type 2 diabetes (UKPDS34). Lancet 1998:352:854-65. http://dx.doi.org/10.1016/\$0140-6736(98)07037-8

5. DCCT/EDIC Research Group. Intensive diabetes therapy and glomerular filtration rate in type 1 diabetes. N Engl J Med 2011;365:2366-76. http://dx.doi.org/10.1056/NEJMoa1111732

6. Writing team for the DCCT/EDIC Research Group. Sustained effect of intensive treatment of type 1 diabetes mellitus on development and progression of diabetic nephropathy: the Epidemiology of Diabetes Intervention and Complications (EDIC) Study. JAMA 2003;290:2159-67. http://dx.doi.org/10.1001/jama.290.16.2159

7. Cryer PE. Hypoglcaemia: the limiting factor in the glycaemic management of type I and || diabetes. Diabetologia 2002;45:937-48. http://dx.doi.org/10.1007/s00125-002-0822-9

8. Cryer PE. Severe hypoglycemia predicts mortality in diabetes. Diabetes Care 2012;35:1814-16. http://dx.doi.org/10.2337/dc12-0749

9. Hirsch IB, Brownlee M. Should minimal blood glucose variability become the gold standard of glycemic control? J Diabetes Complications 2005;19:178-81. http://dx.doi.org/10.1016/j.jdiacomp.2004.10.001

10. DCCT Research Group. The relationship of glycemic exposure (HbA1c) to the risk of development and progression of retinopathy in the Diabetes Control and Complications Trial. Diabetes 1995;44:968-83. http://dx.doi.org/10.2337/diab.44.8.968

11. Mazze R. Making sense of glucose monitoring technologies: from SMBG to CGM. Diabetes Technol Ther 2005; 7:784-7. http://dx.doi.org/10.1089/dia.2005.7.784

12. Mazze R, Lucido D, Langer $O$, et al. Ambulatory Glucose Profile: representation of verified self-monitored blood glucose data. Diabetes Care 1987;10:111-17. http://dx.doi.org/10.2337/diacare.10.1.111

13. Bergenstal RM, Ahmann AJ, Bailey T, et al. Recommendations for standardizing glucose reporting and analysis to optimize clinical decision making in diabetes: the Ambulatory Glucose Profile (AGP). Diabetes Technol Ther 2013;15:198-211. http://dx.doi.org/10.1089/dia.2013.0051

14. Serrano K. FDA supports standardized reporting and analysis on CGM devices. Diabetes Technol Ther 2013;15:348-9. http://dx.doi.org/10.1089/dia.2013.8313

15. Abbott Diabetes Care. System Components [Internet]. 2013 Available from: https://www.abbottdiabetescare.co.uk/ your-products/freestylenavigator/system-components. (Accessed August 2014)

16. Dunn TC, Crouther N. Assessment of the variance of the ambulatory glucose profile over 3 to 20 days of continuous glucose monitoring. Abstract 1054, presented at EASD 2010.

17. Hoss U, Budiman ES, Liu H, Christiansen MP. Continuous glucose monitoring in the subcutaneous tissue over a 14-day sensor wear period. $J$ Diabetes Sci Technol 2013:7:1210-19.

18. Mazze R, Akkerman B, Mettner J. An overview of continuous glucose monitoring and the ambulatory glucose profile. Minnesota Medicine [Internet]. 2011. Available from: www.minnesotamedicine.com/Pastlssues/Pastlssues2011/August2011/ContinuousGlucoseMonitoringandthe Ambulatory.aspx (Accessed August 2014).

19. Cranston IC, Nicholson E. Glucose data and the individualised diabetes consultation. How should we use it? What is enough? Can we ever have too much? Practical Diabetes 2014;31:143-8. http://dx.doi.org/10.1002/pdi.1850 